\title{
Beneficial effect of dehydroepiandrosterone on pulmonary hypertension in a rodent model of pulmonary hypertension in infants
}

\author{
Eric Dumas de la Roque ${ }^{1-3}$, Jean-François Quignard ${ }^{1,2}$, Thomas Ducret ${ }^{1,2}$, Diana Dahan ${ }^{1,2}$, Arnaud Courtois ${ }^{1,2}$, \\ Hugues Begueret ${ }^{3}$, Roger Marthan ${ }^{1-3}$ and Jean-Pierre Savineau ${ }^{1,2}$
}

\begin{abstract}
BACKGROUND: Pulmonary hypertension (PH) is a disease that affects the adult or infant population. Dehydroepiandrosterone (DHEA), a steroid hormone, has been previously shown to prevent and to reverse $\mathrm{PH}$ in an adult rat model. We thus investigated its effect in a rat-pup model of chronic hypoxic $\mathrm{PH}$.
\end{abstract}

METHODS: Animals were maintained for 3 wk in a hypobaric chamber to induce $\mathrm{PH}$, with or without concomitant treatment with DHEA (30 mg/kg every alternate day).

RESULTS: DHEA significantly reduced mean pulmonary artery pressure (measured by right cardiac catheterization), pulmonary artery remodeling (evaluated by histology), and rightventricular hypertrophy (measured by echography and by the Fulton index). At the level of the pulmonary artery smooth muscle cell (PASMC), DHEA increased activity and expression of the large-conductance Ca2+-activated potassium channel $\left(\mathrm{BK}_{\mathrm{Ca}}\right.$ ) (assessed by means of the patch clamp technique). DHEA also inhibited both serotonin- and KCl-induced contraction and smooth muscle cell proliferation.

CONCLUSION: Collectively, these results indicate that DHEA prevents $\mathrm{PH}$ in infant rats and may therefore be clinically relevant for the management of $\mathrm{PH}$ in human infants.

\section{$\mathbf{P}$} ulmonary hypertension $(\mathrm{PH})$ is a disease that affects both adults and infants. $\mathrm{PH}$ is characterized by increased pulmonary vascular pressure and resistance, which can lead, in rare cases in infants, to right-ventricular failure and ultimately to death (1). Increased reactivity to agonists and remodeling of small pulmonary arteries (PAs) are landmarks of $\mathrm{PH}$ $(2,3)$. In infants, there are a variety of $\mathrm{PH}$ phenotypes, some of which are specific to this age group: (i) $\mathrm{PH}$ secondary to congenital heart disease with a left-right shunt, (ii) persistent $\mathrm{PH}$ of the newborn due to the absence of a drop in neonatal pulmonary resistance, (iii) acute or chronic pulmonary disease induced by hypoxemia, and (iv) idiopathic forms $(4,5)$. Pharmacological treatments that mainly aim at vasodilating PAs, e.g., prostanoid analog, endothelin receptor antagonists, or phosphodiesterase inhibitors $(2,6)$, still need to be comprehensively evaluated in pediatric patients. It is thus essential to develop new treatments to prevent and/or reverse $\mathrm{PH}$ in this population.

Dehydroepiandrosterone (DHEA) is the most abundant adrenal steroid, and serum concentration of its sulfate ester is approximately 20 -fold higher than that of any other circulating steroid hormone $(7,8)$. In different models of adult rats with $\mathrm{PH}$, we $(9)$ and others $(10,11)$ have shown that DHEA prevents and reverses $\mathrm{PH}$ and the resulting right-ventricular (RV) hypertrophy as well as small PA remodeling. However, similar studies have not been performed in newborn or infant animals. We have thus investigated the effect of DHEA in a model of infant rats in which $\mathrm{PH}$ was induced. We have observed that chronic treatment with DHEA $(30 \mathrm{mg} / \mathrm{kg}$ every alternate day) is able to prevent $\mathrm{PH}$ and its associated cardiovascular alterations such as RV hypertrophy, pulmonary vascular hyperreactivity, and smooth muscle cell proliferation.

\section{RESULTS}

Beneficial Effect of DHEA on the Juvenile Rat Model of PH Exposure to chronic hypoxia $(\mathrm{CH})$ for $3 \mathrm{wk}$ induced $\mathrm{PH}$ in juvenile rats $(\mathrm{CH}$ rats), as revealed by the increase in mean pulmonary artery pressure (PAP) $(27 \pm 3.2 \mathrm{~mm} \mathrm{Hg}, n=8$, vs. $14.7 \pm 2.3 \mathrm{~mm} \mathrm{Hg}, n=6, P<0.05$, in $\mathrm{CH}$ and control rats, respectively) (Figure 1a). CH also induced RV hypertrophy, as demonstrated by a significant increase (75\%) in the RV thickness measured by cardiac echography (Figure 1b). Furthermore, the pulmonary artery acceleration time decreased, confirming the presence of $\mathrm{PH}$ in infants (Figure 1c). Chronic treatment of $\mathrm{CH}$ rats with DHEA (assessed by the rise in its circulating concentration to $503 \pm 311 \mathrm{nmol} / \mathrm{l}(n=5))$ prevented $\mathrm{CH}$-induced PH. Indeed mean PAP, RV thickness, and the pulmonary artery acceleration time of CH-DHEA rats were not significantly different from those of control rats (Figure 1a-c). These data demonstrate that DHEA treatment prevented the pulmonary hemodynamic changes induced by $\mathrm{CH}$. 
a

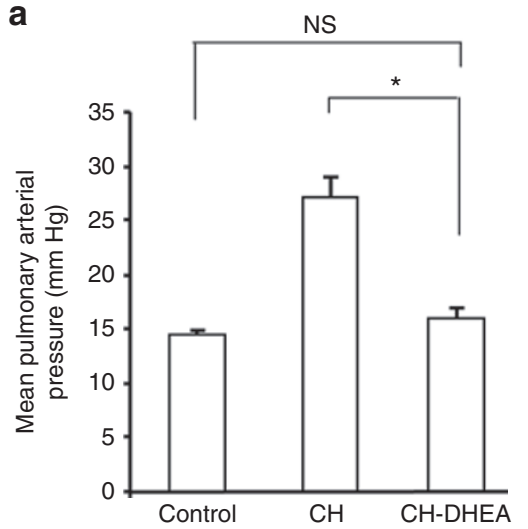

b

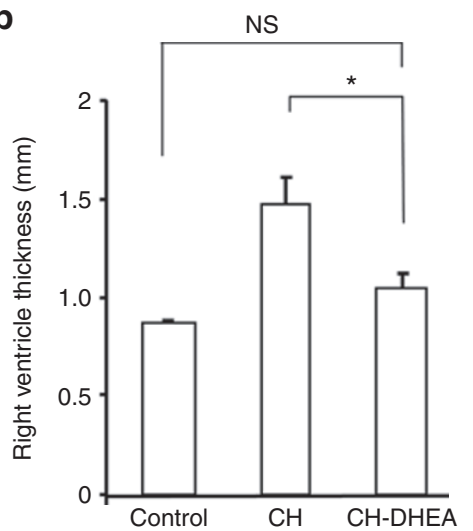

C

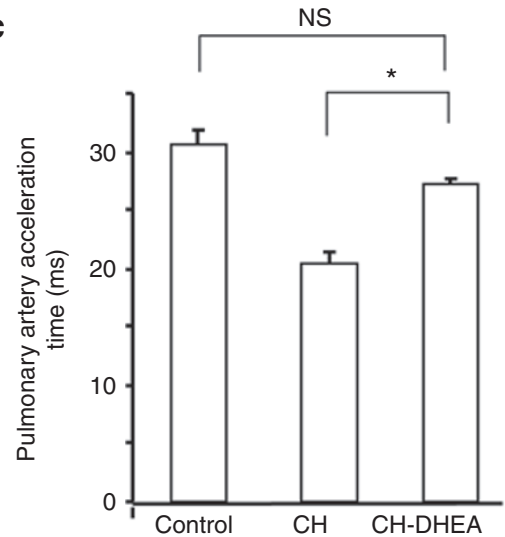

Figure 1. Chronic DHEA treatment prevents chronic hypoxia-induced PH in juvenile rats. Chronic hypoxia (CH) exposure for 3 wk induced (a) a significant increase in mean PAP, (b) a significant increase in RV wall thickness, and (c) a decrease in pulmonary artery acceleration time value. DHEA treatment $(30 \mathrm{mg} / \mathrm{kg}$ orally every alternate day, CH-DHEA juvenile rats) prevented all these changes. Each bar represents the mean value \pm SEM from 6 to 12 animals. ${ }^{*} P<0.05$ vs. CH. DHEA, dehydroepiandrosterone; NS, not significant; PAP, pulmonary artery pressure; PH, pulmonary hypertension; RV, right-ventricular.
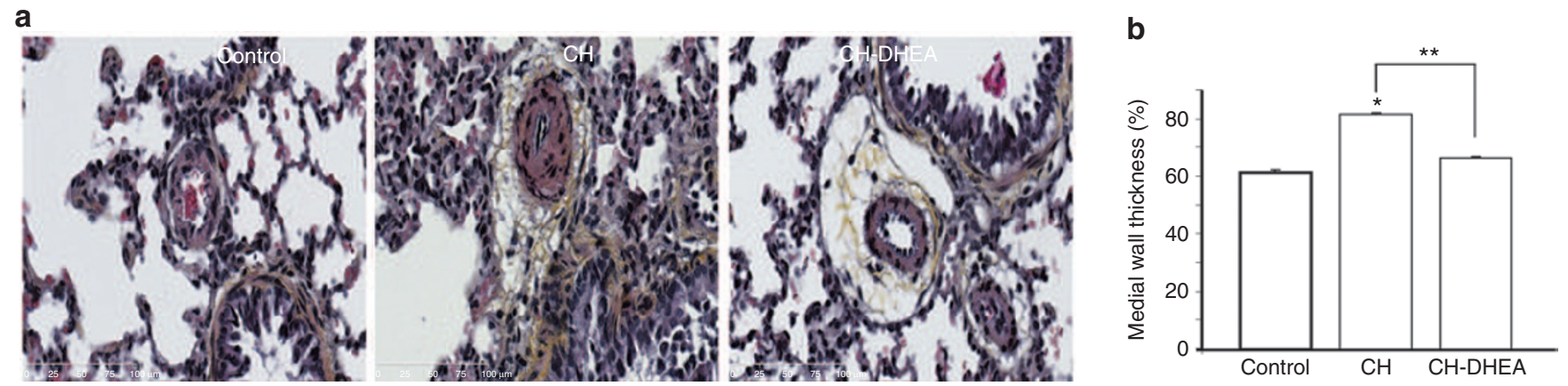

Figure 2. Effects of oral DHEA on pulmonary artery (PA) remodeling. (a) Typical image of pulmonary vessels from each juvenile group $\mathrm{CH}$ induced a significant increase in the PA wall thickness that was prevented by DHEA treatment. Juvenile rats were exposed to chronic hypoxia (CH) for $3 \mathrm{wk}$, or $\mathrm{CH}$ plus treatment with DHEA (CH-DHEA) for 3 wk as in Figure 1a. (b) Each bar represents the mean \pm SEM of wall thickness and lumen area. Ten measurements were made per rat by an investigator blinded to the treatment groups. Bars $=100 \mathrm{~m}$. ${ }^{*} P<0.05$ vs. control; ${ }^{* *} P<0.05$ vs. CH. DHEA, dehydroepiandrosterone.

Because remodeling and hyperreactivity of PA are hallmarks of PH in adults, we next studied the effect of DHEA on these characteristics in infants.

\section{Antiremodeling Effect of DHEA in the Pulmonary Vasculature}

$\mathrm{CH}$-induced $\mathrm{PH}$ is thus characterized by a remodeling of the pulmonary vasculature due to smooth muscle hypertrophy (Figure 2a). Morphometric analyses of vascular wall thickness showed that $\mathrm{CH}$ increased this parameter by $33 \%$ in small PAs (61.5 $\pm 1 \%$ in control rats vs. $81.7 \pm 0.8 \%$ in $\mathrm{CH}$ rats) (Figure 2a,b). DHEA significantly prevented this $\mathrm{CH}$-induced increase in vessel wall thickness (66.4 $\pm 0.8 \%$ ) (Figure 2a,b). All the above results confirm that DHEA treatment prevents PA remodeling associated with $\mathrm{PH}$.

We then studied the effect of DHEA on in vitro proliferation of pulmonary artery smooth muscle cells (PASMCs) induced by three different mitogens: fetal calf serum (FCS), serotonin (5-HT) (a well-known mitogenic agent in PASMCs) (12-14), and hypoxia. Dose-dependent proliferation induced by FCS was inhibited by DHEA ( $50 \mu \mathrm{mol} / \mathrm{l}$, Figure 3a). Exposure of PASMCs to $30 \mu \mathrm{mol} / 15-\mathrm{HT}$ for $24 \mathrm{~h}$ also induced a significant proliferation (twofold increase), albeit of lesser magnitude as compared with $10 \%$ FCS. This 5 -HT-induced proliferation was inhibited by the additional presence of DHEA $(50 \mu \mathrm{mol} / \mathrm{l})$ in the culture medium (Figure 3b). Finally, we observed that hypoxia ( $10 \%$ oxygen, $5 \% \mathrm{CO}_{2}$ for $24 \mathrm{~h}$ ) potentiated the proliferative effect of FCS $(0.2-10 \%)$, and again the additional presence of DHEA prevented this effect (Figure 3c).

\section{DHEA Reduced PA Contractile Responses to Serotonin and $\mathrm{KCl}$}

We evaluated the effect of two vasoconstrictor agents 5-HT and $\mathrm{KCl}$, each acting via different membrane mechanisms: a $\mathrm{G}$ protein-coupled membrane receptor-dependent pathway and a direct membrane depolarization, respectively. Both agents induced concentration-dependent contractile responses in intrapulmonary arteries (IPAs) from control rats (Figure 4a,b). In IPAs from $\mathrm{CH}$ rats, the response to $5-\mathrm{HT}$ was markedly increased as compared with those of control rats (Figure 4a). The efficacy $\left(\mathrm{E}_{\max }\right)$ of 5 -HT increased by $80.5 \%(p<.0 .05)$. However, the potency $\left(\mathrm{EC}_{50}\right)$ was not significantly altered $(4.1 \pm 0.4$ and $4.6 \pm 0.5 \mu \mathrm{mol} / \mathrm{l}$, respectively). In IPAs from CH-DHEA rats, 5 -HT-induced contraction was statistically reduced for low concentrations $\left(\mathrm{EC}_{50}: 11 \pm 0.4 \mu \mathrm{mol} / \mathrm{l}\right)$ (Figure 4a). Regarding $\mathrm{KCl}(60 \mathrm{mmol} / \mathrm{l})$, the efficacy was not significantly altered by $\mathrm{CH}$, but its potency was increased $\left(\mathrm{EC}_{50}=18 \pm 1.5 \mathrm{mmol} / \mathrm{l}\right.$ and $32 \pm 2.8 \mathrm{mmol} / \mathrm{l}$ in $\mathrm{CH}$ and control rats, respectively, $p<0.05$ ) 
a

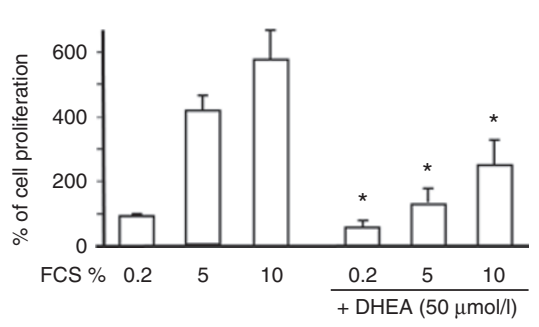

b

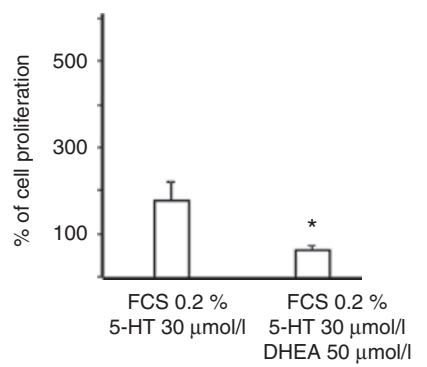

C

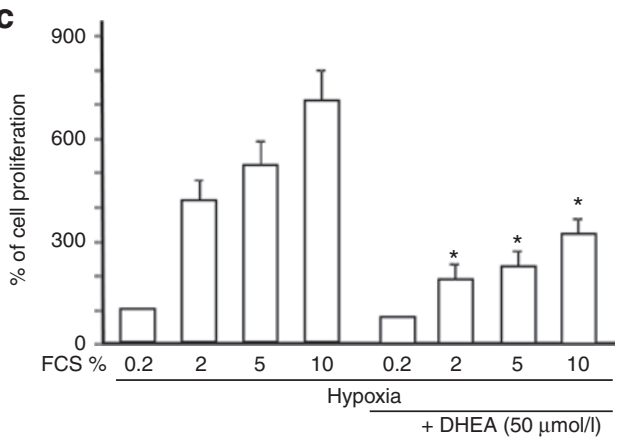

Figure 3. Effects of DHEA on PASMC proliferation. (a, b) DHEA (24h)-inhibited cell proliferation induced by different concentrations of FCS or by serotonin. (c) DHEA inhibited cell proliferation induced by different concentrations of FCS in hypoxic condition that mimic $\mathrm{CH}$ (cells were cultured in the presence of $10 \%$ oxygen and $5 \% \mathrm{CO}_{2}$ ). $\mathrm{CH}$, chronic hypoxia; DHEA, dehydroepiandrosterone; FCS, fetal calf serum; PASMC, pulmonary artery smooth muscle cell; 5 -HT, serotonin. ${ }^{*} P<0.05$ vs. value obtained in the absence of DHEA.

a

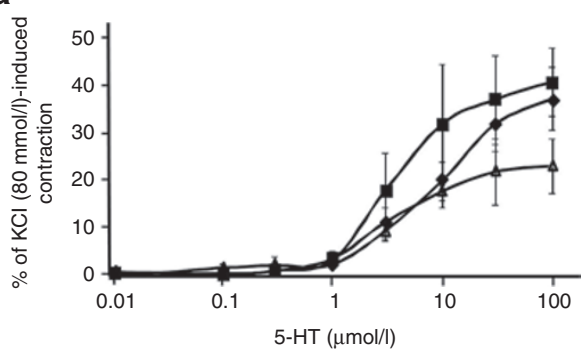

C

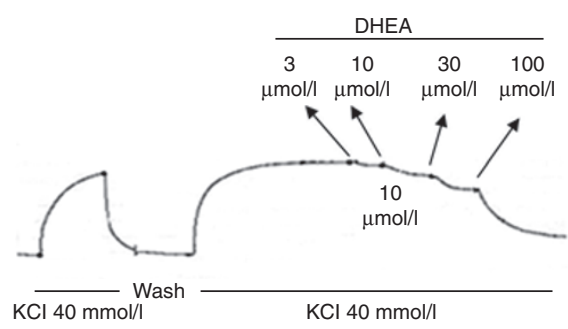

b

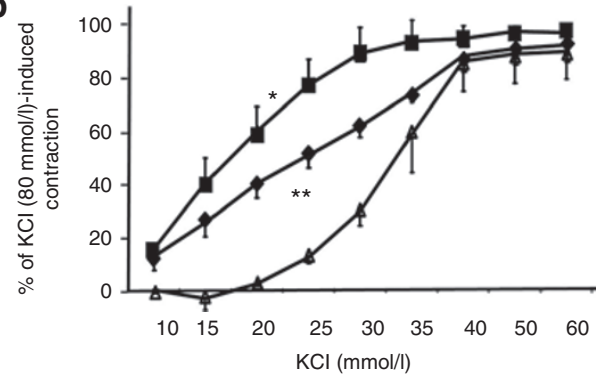

d

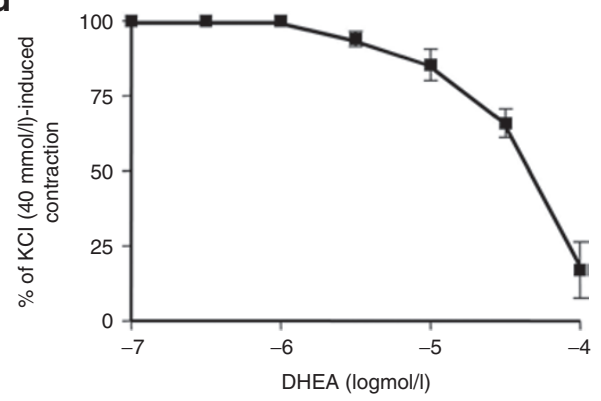

Figure 4. Effects DHEA on intrapulmonary artery (IPA) reactivity. (a) Cumulative concentration-response curves to serotonin (5-HT) (0.01-100 $\mu$ mol/l) from IPA rings of control (triangles), $\mathrm{CH}$ (squares), and CH-DHEA (diamonds) juvenile rats. (b) Cumulative concentration-response curves to $\mathrm{KCl}$ (2.5-60 mmol/l) from IPA rings of control, $\mathrm{CH}$, and CH-DHEA juvenile rats. Data are presented as mean \pm SEM for 2-7 animals and are expressed as a percentage of the $\mathrm{KCl}(80 \mathrm{mmol} / \mathrm{l})$ solution-induced response. ${ }^{*} P<0.05 \mathrm{vs}$. control, ${ }^{* *} P<0.05 \mathrm{vs}$. $\mathrm{CH}$. (c,d) Acute effect of DHEA. (c) Original recording of $\mathrm{KCl}(40 \mathrm{mmol} / \mathrm{l})$-induced contraction in IPA ring from control rat and of in vitro application of DHEA (3-100 $\mu$ mol/l). (d) Concentration-response curve for the effect of DHEA on the $\mathrm{KCl}$-induced contraction. Data are presented as mean \pm SEM for 2-7 animals and are expressed as a percentage of the $\mathrm{KCl}(40 \mathrm{mmol} / \mathrm{l})$ solution-induced response. $\mathrm{CH}$, chronic hypoxia; DHEA, dehydroepiandrosterone.

(Figure 4b). DHEA treatment significantly reversed the $\mathrm{CH}$ effect on $\mathrm{EC}_{50}$ value $(24 \pm 1.9 \mathrm{mmol} / \mathrm{l})$, without significant effect on $\mathrm{E}_{\max }$ (Figure 4b). These results indicate that DHEA partially reverses $\mathrm{CH}$-induced hyperreactivity to vasoconstrictor agents. Furthermore, acute applications of DHEA $(1-100 \mu \mathrm{mol} / \mathrm{l})$ to 40 $\mathrm{mmol} / \mathrm{l} \mathrm{KCl}$-precontracted IPAs from control rats relaxed the vessels with an $\mathrm{EC}_{50}$ of $40 \mu \mathrm{mol} / \mathrm{l}$ (Figure $4 \mathrm{c}$,d), thus indicating that DHEA is a direct vasodilating drug.

DHEA Prevented CH-Induced Decrease in Outward Potassium Currents: Involvement of Large-Conductance $\mathrm{Ca}^{2+}$-Activated Potassium Channel ( $\mathrm{BK}_{\mathrm{Ca}_{\mathrm{a}}}$ ) Current

Contraction and thus hyperreactivity of PAs are, at least in part, dependent on the membrane potential value, which is mainly governed by the activity of potassium channels $(15,16)$. The amplitude of whole-cell potassium currents elicited from a holding potential from $-80 \mathrm{mV}$ was decreased in PASMCs from $\mathrm{CH}$ but increased in PASMCs from CH-DHEA rats as compared with control rats (Figure $5 \mathbf{a}, \mathbf{b}, \mathbf{d}$ ). This outward current is a mix of voltage-gated $(\mathrm{Kv})$ and calcium-activated $\left(\mathrm{K}_{\mathrm{Ca}}\right)$ potassium current. On the one hand, iberiotoxin (100 nmol/l), a selective inhibitor of $\mathrm{BK}_{\mathrm{Ca}}(17)$, decreased outward currents $(34 \pm 5 \%$ of inhibition at $+50 \mathrm{mV}$ ) (Figure $5 \mathrm{c}$ ), whereas, on the other hand, residual current was almost entirely inhibited by 4 -aminopyridine ( $5 \mathrm{mmol} / \mathrm{l}$ ), a nonspecific inhibitor of $\mathrm{K}_{\mathrm{V}}$ channels (Figure $5 \mathrm{c}$ ). At a holding potential of $-20 \mathrm{mV}$, which inactivates $\mathrm{Kv}$, the potassium current was mainly a $\mathrm{BK}_{\mathrm{Ca}}$ current, given that it was inhibited by iberiotoxin $(91 \pm 5 \%$, in control 


\section{Articles $\mid$ Dumas de la Roque et al.}

a

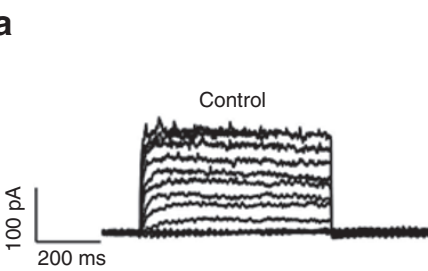

C

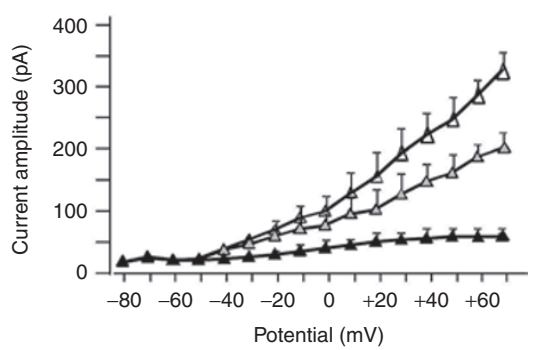

d

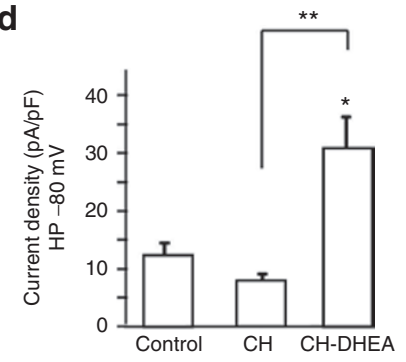

b

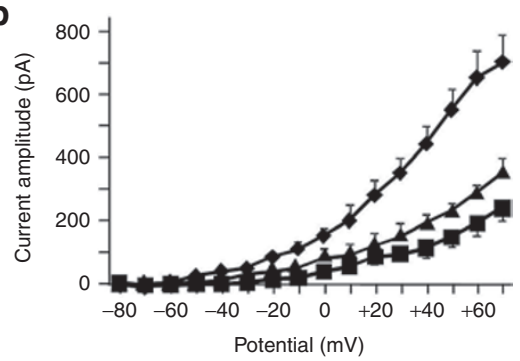

e

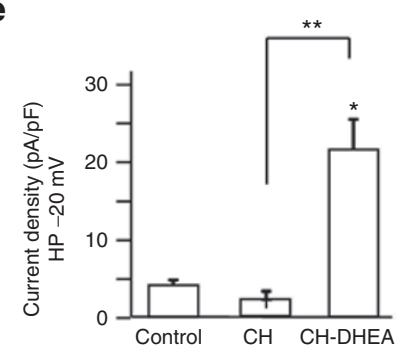

Figure 5. Effect of DHEA treatment on whole-cell potassium current from PASMCs. (a) Family of currents elicited by incremental 10-mV depolarizing steps from -80 to $+60 \mathrm{mV}$ in PASMCs from control (triangles), CH (squares), and CH-DHEA (diamonds) juvenile rats. (b) Current voltage relationship curve of the potassium current (holding potential $-80 \mathrm{mV}$, step depolarization by increment of $10 \mathrm{mV}$ ) for the three conditions. (c) Inhibitory effect of iberiotoxin $(100 \mathrm{nmol} / \mathrm{l})$ (white triangles) alone or associated with 4-aminopyridine $(5 \mathrm{mmol} / \mathrm{l})$ (gray triangles), inhibitors of BK $\mathrm{C}_{\mathrm{c}} \mathrm{s}$ and voltage-gated potassium channels, respectively, on outward current in PASMCs from control juvenile rats (white triangles). (d) Current density of outward current amplitudes in PASMCs (holding potential of $-80 \mathrm{mV}$ ) (recording of voltage-gated channels and $\mathrm{BK}_{\mathrm{C}_{\mathrm{a}}} \mathrm{s}$ ) or (e) with a holding potential of $-20 \mathrm{mV}$ (recording of $\mathrm{BK}_{\mathrm{Ca}} \mathrm{s}$ mainly). $\mathrm{BK}_{\mathrm{Ca}}$ current was significantly smaller in $\mathrm{CH}$ cells but was greater in $\mathrm{CH}$-DHEA cells as compared with control cells. Results represent the mean \pm SEM. ${ }^{*} P<0.05$ indicates significant difference as compared with control cells. ${ }^{* *} P<0.05$ vs. $\mathrm{CH}$. BK $\mathrm{Ca}_{\mathrm{C}^{\prime}}$ large-conductance $\mathrm{Ca} 2+$-activated potassium channel; $\mathrm{CH}$, chronic hypoxia; DHEA, dehydroepiandrosterone; PASMC, pulmonary artery smooth muscle cell.

rats, data not shown). Figure 5e shows that the current density (at a $-20 \mathrm{mV}$ holding potential) was significantly decreased in PASMCs from $\mathrm{CH}$ rats and largely increased in PASMCs from CH-DHEA rats. These results indicate that chronic DHEA treatment increases mainly $\mathrm{BK}_{\mathrm{Ca}}$ current. Recording of iberiotoxin-sensitive $\mathrm{BK}_{\mathrm{Ca}}$ unitary current $(180 \mathrm{pS}, n=10)$ with the cell-attached configuration (pipette filled with the extracellular solution of the whole-cell mode) indicated that DHEA treatment did not change the open probability of the channel (data not shown). However, there were more cell-attached patches in which a current was recorded in CH-DHEA rats than in $\mathrm{CH}$ rats ( $70 \%$ and $25 \%, n=6$ and 12 , respectively) indicating that DHEA increased the number of $\mathrm{BK}_{\mathrm{Ca}}$ channels.

\section{DISCUSSION}

The current study shows that, as in adults, DHEA prevents the onset of chronic hypoxia-induced $\mathrm{PH}$ in juvenile rats. More specifically, DHEA reduces the increase in mean PAP and prevents associated PA remodeling and hyperreactivity, as well as RV hypertrophy.

Regarding the animal model, the following two issues deserve discussion. First, our study was conducted in pups aged $15 \mathrm{~d}$ whose lung maturation is comparable to the early childhood stage in humans (18) but substantially different from neonatal hypoxic $\mathrm{PH}$ described in pups exposed to hypoxia immediately after birth $(19,20)$. Our present model aimed to mimic hypoxic $\mathrm{PH}$ secondary to chronic or acute respiratory disease in children such as bronchopulmonary dysplasia, acute viral bronchiolitis, or severe pulmonary infection. Second, because our aim was to evaluate the effect of DHEA in PH, we did not include an additional group of healthy juvenile rats treated with DHEA only, because we have previously demonstrated the absence of modification of pulmonary and systemic hemodynamic in air-exposed adult rats treated with DHEA (9).

The active dose of DHEA used in our experiments is identical to that given in our previous studies $(9,21)$. This chronic oral protocol yields a circulating concentration of DHEA in the range of $\geq 10^{-7} \mathrm{~mol} / \mathrm{l}$, similar to that commonly used in in vitro studies. Therefore our data are of pharmacological relevance (9).

In adults, PA remodeling is one of the main causes of increased pulmonary vascular resistance in PH. Likewise, in the present study, in juvenile rats, $\mathrm{CH}$ induced PA remodeling as a consequence of an increase in vascular wall thickness. This effect was prevented by DHEA treatment (Figure 2). Remodeling of PA during $\mathrm{PH}$ in adult animals as well as in humans is mainly a result of increased proliferation of PASMCs $(22,23)$. We addressed the possible effect of DHEA on this key step in the development of $\mathrm{PH}$ in infants by studying the proliferation of PASMCs in vitro. The stimulating effect of FCS, 5-HT, or hypoxia was, in each case, prevented by the additional presence of DHEA in the culture medium (Figure 3). The proliferative actions of 5-HT or hypoxia on PASMCs have mainly been ascribed to their effect on the RhoA/ROCK pathway or on hypoxia inducible factor $1 \alpha$ levels, respectively (24-26). Of note, DHEA has also 
been shown to inhibit RhoA/ROCK pathway and to decrease hypoxia inducible factor- $1 \alpha$ in PASMCs $(11,27)$.

PA hyperreactivity is an additional key feature in $\mathrm{PH}$. In the present study, we have shown that DHEA prevents $\mathrm{CH}$-induced hyperactivity to 5-HT and $\mathrm{KCl}$ (Figure 4). The effect of DHEA on 5-HT-induced contraction may involve an effect on a signaling pathway that mobilizes intracellular calcium (9) given that we have previously demonstrated that $\mathrm{CH}$ modifies resting cytosolic calcium concentration and agonist-induced contraction in PASMCs from the adult rat (28). The effect of DHEA on $\mathrm{KCl}$-induced contraction may involve ionic conductance because $\mathrm{CH}$ depolarizes the cell membrane and downregulates potassium channels in adult rat and human PASMCs $(29,30)$. Likewise, in the present study, we have shown that $\mathrm{CH}$ decreases potassium currents in PASMCs from juvenile rats and that this effect is prevented following DHEA treatment. The major component of the potassium current increase is related to an increased number of $\mathrm{BK}_{\mathrm{Ca}} \mathrm{s}$ in CH-DHEA rats. This result is in accordance with a previous study conducted in adult rats (9) revealing an increase in $\mathrm{BK}_{\mathrm{Ca}}$ expression in PASMCs from $\mathrm{CH}$-DHEA rats in comparison with $\mathrm{CH}$ rats. Finally, the acute application of DHEA relaxed $\mathrm{KCl}$-preconstricted arterial rings in a concentration-dependent manner (Figure 4c), suggesting an inhibitory effect of DHEA on voltage-dependent calcium channels. This latter result is also in agreement with a recent finding showing that DHEA inhibits T-type calcium channels in PASMCs from adult rat (31).

The beneficial effect of DHEA in PH has also been observed in the monocrotaline-induced $\mathrm{PH}$ rat model, which is closer to the pathophysiology of idiopathic $\mathrm{PH}$ (11), although further studies investigating its effect on plexiform lesions remain to be performed. With respect to the mechanism of action, in addition to the modulation of $\mathrm{Ca}^{2+}$-activated potassium channel expression and activity, other cellular mechanisms have already been demonstrated and include a protective effect on the vascular endothelium (32), an activation of the RhoA/Rho kinase signaling pathway (11), a decrease in vascular remodeling with activation of apoptosis, and a decrease in cellular proliferation via the inhibition of transcription factors such as hypoxia inducible factor- 1 or nuclear factor of activated $\mathrm{T}$ cell $(27,33)$.

In adult humans, we recently demonstrated, in a pilot study conducted in $\mathrm{PH}$ associated with chronic obstructive pulmonary disease, the excellent clinical tolerance of DHEA in general and particularly regarding the respiratory status (34). In conclusion, the present study indicates that DHEA displays some preventive actions on $\mathrm{PH}$ in a juvenile rat model. Owing to its lack of side effects, it could be assumed that DHEA may prove to be a valuable molecule that deserves further clinical studies in PH secondary to respiratory diseases in infants.

\section{METHODS}

\section{Animals and Chronic Hypoxia Exposure}

The investigation was carried out in agreement with the Guide for the Care and Use of Laboratory Animals published by the US National Institutes of Health (NIH) (NIH Publication No. 85-23, revised 1996) and approved by the local institutional animal care and use committee (protocol number: AP 2/11/2005, Bordeaux 2 University). Fifteen days after birth, Wistar female rats with their pups were randomized and separated into three groups. The first group (control) was housed in ambient room air, the second group $(\mathrm{CH})$ was exposed to chronic hypoxia for $3 \mathrm{wk}$ in a hypobaric chamber $(50 \mathrm{kPa})$, and the third group (CH-DHEA) was exposed to chronic hypoxia and was treated concomitantly with DHEA $(30 \mathrm{mg} / \mathrm{kg}$ orally every alternate day). Animals were killed after the exposition phase immediately prior to in vitro or following in vivo experiments, which were performed according to the following protocols.

\section{Assessment of PH: Hemodynamic and Echocardiographic Measurements}

PAP was measured in anesthetized and closed-chest rats with 2.5-Fr catheters (Vigon SA, Ecouen, France) inserted through the right jugular vein then through the right atria and the right ventricle into the PA as previously described (35). Echocardiography measurements were also conducted as previously described (36). M-mode measurement of RV thickness was performed in a trans-ventricular short-axis view at the level of the papillary muscles. The pulmonary artery acceleration time was measured from the time of onset of systolic flow to peak pulmonary outflow velocity.

\section{Histology}

For morphometric studies, vessel rings were fixed in $4 \%$ formaldehyde solution. Multiple 5- $\mu \mathrm{m}$ transverse slides were processed in paraffin wax and stained with hematoxylin and eosin, elastic stain, and orcein-picroindigo-carmine. Area of the entire vessel (VA), area of the lumen (LA), and percentage vessel wall thickness [(VA - LA) / VA $\times 100]$ were measured in $80-100 \mu \mathrm{m}$ PA as previously described (37). Fifty measurements were made per rat by an investigator blinded to the treatment groups.

\section{Isolation and Culture of PASMCs}

IPAs (first- and second-order branches) of juvenile rats were mechanically dissected. Freshly isolated PASMCs and cultured PASMCs were obtained using an enzymatic dissociation method already described $(38,39)$. Cells were used between 2 and $24 \mathrm{~h}$ after isolation for electrophysiology or later for cell proliferation assay. Smooth muscle characteristics of isolated cells were confirmed by positive immunostaining with an anti- $\alpha$ smooth muscle actin antibody (Sigma, Saint Quentin Fallavier, France).

\section{Electrophysiological Recordings}

Channel activity was recorded from cell-attached or whole-cell patches using the technique described by Hamill et al. (40) and previously applied to PASMCs $(12,38)$. Stimulus control, data acquisition, analysis, and processing were carried out on a PC computer using Pclamp 10 software (Molecular Devices, Foster City, CA). Current density was expressed as the maximum amplitude of the current per capacitance unit. For whole-cell recording, the bathing solution was composed of the following (in mmol/l): $5 \mathrm{KCl}, 140 \mathrm{NaCl}, 2.2 \mathrm{CaCl}_{2}$, $1.2 \mathrm{MgCl}_{2}, 14 \mathrm{D}$-glucose, and $10 \mathrm{~N}$-2-hydroxyethylpiperazine-N'-2ethanesulfonic acid ( $\mathrm{pH}=7.4$, adjusted with $\mathrm{NaOH}$ ), and the pipette solution had the following composition (in mmol/l): $5 \mathrm{NaCl}, 50 \mathrm{KCl}$, $65 \mathrm{~K}_{2} \mathrm{SO}_{4}, 2 \mathrm{MgCl}_{2}, 2 \mathrm{ATP}$, and $10 \mathrm{~N}$-2-hydroxyethylpiperazine$\mathrm{N}^{\prime}$-2-ethanesulfonic acid, ( $\mathrm{pH} 7.3$, adjusted with $\mathrm{KOH}$ ). For cellattached recordings, the bating solution included the following (in $\mathrm{mmol} / \mathrm{l}): 140 \mathrm{KCl}, 2.2 \mathrm{CaCl}_{2}, 1.2 \mathrm{MgCl}_{2}, 14 \mathrm{D}$-glucose, and $10 \mathrm{~N}-2$ hydroxyethylpiperazine- $\mathrm{N}^{\prime}-2$-ethanesulfonic acid ( $\mathrm{pH}=7.4$, adjusted with $\mathrm{KOH}$ ), and the pipette solution had the following composition (in mmol/l): $140 \mathrm{NaCl}, 2.2 \mathrm{CaCl}_{2}, 1.2 \mathrm{MgCl}_{2}, 14 \mathrm{D}$-glucose, and 10 $\mathrm{N}$-2-hydroxyethylpiperazine-N'-2-ethanesulfonic acid $(\mathrm{pH}=7.4$, adjusted with $\mathrm{NaOH}$ ). Drugs were delivered to the cells via pressure ejection from a glass pipette. All experiments were performed at room temperature.

\section{Isometric Contraction Measurement}

IPAs (first- and second-order branches) were dissected free of connective tissue. Rings (1.6-2 mm length) were mounted in a Mulvany myograph (model 610M, DMT, Aarhus, Denmark), bathed in Krebs 
solution (in mmol/l: $119 \mathrm{NaCl}, 4.7 \mathrm{KCl}, 1.5 \mathrm{CaCl}_{2}, 1.17 \mathrm{MgSO}_{4}, 1.18$ $\mathrm{KH}_{2} \mathrm{PO}_{4}, 25 \mathrm{NaHCO}_{3}$, and $5.5 \mathrm{D}$-glucose), maintained at $37^{\circ} \mathrm{C}$, and gassed with a mixture of $95 \% \mathrm{O}_{2}$ and $5 \% \mathrm{CO}_{2}(\mathrm{pH}=7.4)$. The optimal resting tension for IPAs of rats maintained in normoxic or hypoxic conditions corresponded to an equivalent transmural pressure of 30 or $50 \mathrm{~mm} \mathrm{Hg}$, respectively. A cumulative concentration-response curve to serotonin $(5-\mathrm{HT}, 10 \mathrm{nmol} / \mathrm{l}-100 \mu \mathrm{mol} / \mathrm{l})$ or potassium $(10-$ $60 \mathrm{mmol} / \mathrm{l})$ was then constructed.

\section{Cell Proliferation Assay}

Quantitative determination of DNA synthesis using the Cell Proliferation ELISA, BrdU colorimetric method (Roche Applied Science, Sandhofer, Germany), was used to assess PASMC proliferation according to the manufacturer's instructions as previously described (12). BrdU incorporation was measured during $2 \mathrm{~h}$. Each condition was tested in triplicate wells.

\section{Reagents}

General salts were from VWR International (Fontenay-sous-Bois, France). All other chemicals were purchased from Sigma.

\section{Data and Statistical Analysis}

Results are expressed as mean \pm SEM. Intergroup differences were assessed by a Kruskal-Wallis ANOVA test, as appropriate. In experiments comparing two conditions, a nonpaired Mann-Whitney test was used. The letter $(n)$ refers to the animal sample size or to the number of cells in the relevant experiments. A $P$-value $<0.05$ was considered significant.

\section{ACKNOWLEDGMENTS}

The authors thank G. Simon and H. Crevel (INSERM U 1045, Université de Bordeaux, France) for technical assistance and Michael Fayon for the correction of the article.

\section{STATEMENT OF FINANCIAL SUPPORT}

This work was funded, in part, by grants from the "Fondation de France" (2008002719), the "Conseil Régional d'Aquitaine" (2011), and the "Université Bordeaux Segalen" (Preciput 2010 JFQ).

Disclosure: The authors declare no conflict of interest.

\section{REFERENCES}

1. Rubin LJ. Primary pulmonary hypertension. N Engl J Med 1997;336: $111-7$.

2. Humbert M, Morrell NW, Archer SL, et al. Cellular and molecular pathobiology of pulmonary arterial hypertension. J Am Coll Cardiol 2004;43:Suppl 12:13S-24S.

3. Mandegar M, Fung YC, Huang W, Remillard CV, Rubin LJ, Yuan JX. Cellular and molecular mechanisms of pulmonary vascular remodeling: role in the development of pulmonary hypertension. Microvasc Res 2004;68:75-103.

4. Haworth SG. Pulmonary hypertension in the young. Heart 2002;88: 658-64.

5. Haworth SG, Beghetti M. Assessment of endpoints in the pediatric population: congenital heart disease and idiopathic pulmonary arterial hypertension. Curr Opin Pulm Med 2010;16:Suppl 1:S35-41.

6. Archer SL, Weir EK, Wilkins MR. Basic science of pulmonary arterial hypertension for clinicians: new concepts and experimental therapies. Circulation 2010;121:2045-66.

7. Baulieu EE, Corpechot C, Dray F, et al. An adrenal-secreted "androgen": dehydroisoandrosterone sulfate. Its metabolism and a tentative generalization on the metabolism of other steroid conjugates in man. Recent Prog Horm Res 1965;21:411-500.

8. Migeon CJ, Keller AR, Lawrence B, Shepard TH 2nd. Dehydroepiandrosterone and androsterone levels in human plasma: effect of age and sex; dayto-day and diurnal variations. J Clin Endocrinol Metab 1957;17:1051-62.

9. Bonnet $\mathrm{S}$, Dumas-de-La-Roque E, Bégueret H, et al. Dehydroepiandrosterone (DHEA) prevents and reverses chronic hypoxic pulmonary hypertension. Proc Natl Acad Sci USA 2003;100:9488-93.
10. Hampl V, Bíbová J, Povýsilová V, Herget J. Dehydroepiandrosterone sulphate reduces chronic hypoxic pulmonary hypertension in rats. Eur Respir J 2003;21:862-5.

11. Homma N, Nagaoka T, Karoor V, et al. Involvement of RhoA/Rho kinase signaling in protection against monocrotaline-induced pulmonary hypertension in pneumonectomized rats by dehydroepiandrosterone. Am J Physiol Lung Cell Mol Physiol 2008;295:L71-8.

12. Ducret T, Guibert C, Marthan R, Savineau JP. Serotonin-induced activation of TRPV4-like current in rat intrapulmonary arterial smooth muscle cells. Cell Calcium 2008;43:315-23.

13. Eddahibi S, Fabre V, Boni C, et al. Induction of serotonin transporter by hypoxia in pulmonary vascular smooth muscle cells. Relationship with the mitogenic action of serotonin. Circ Res 1999;84:329-36.

14. Rodat-Despoix L, Crevel H, Marthan R, Savineau JP, Guibert C. Heterogeneity in 5-HT-induced contractile and proliferative responses in rat pulmonary arterial bed. J Vasc Res 2008;45:181-92.

15. Casteels R, Kitamura K, Kuriyama H, Suzuki H. Excitation-contraction coupling in the smooth muscle cells of the rabbit main pulmonary artery. J Physiol (Lond) 1977;271:63-79.

16. Yuan XJ. Voltage-gated $\mathrm{K}+$ currents regulate resting membrane potential and [Ca2+]i in pulmonary arterial myocytes. Circ Res 1995;77:370-8.

17. Galvez A, Gimenez-Gallego G, Reuben JP, et al. Purification and characterization of a unique, potent, peptidyl probe for the high conductance calcium-activated potassium channel from venom of the scorpion Buthus tamulus. J Biol Chem 1990;265:11083-90.

18. Zoetis T, Hurtt ME. Species comparison of lung development. Birth Defects Res B Dev Reprod Toxicol 2003;68:121-4.

19. Xu EZ, Kantores C, Ivanovska J, et al. Rescue treatment with a Rho-kinase inhibitor normalizes right ventricular function and reverses remodeling in juvenile rats with chronic pulmonary hypertension. Am J Physiol Heart Circ Physiol 2010;299:H1854-64.

20. Ziino AJ, Ivanovska J, Belcastro R, et al. Effects of rho-kinase inhibition on pulmonary hypertension, lung growth, and structure in neonatal rats chronically exposed to hypoxia. Pediatr Res 2010;67:177-82.

21. Dumas de La Roque E, Bellance N, Rossignol R, et al. DHEA reverses chronic hypoxia/reoxygenation-induced right ventricular dysfunction in rats. Eur Respir J 2012;40:1420-9.

22. Jeffery TK, Wanstall JC. Pulmonary vascular remodeling: a target for therapeutic intervention in pulmonary hypertension. Pharmacol Ther 2001;92:1-20.

23. Morrell NW, Adnot S, Archer SL, et al. Cellular and molecular basis of pulmonary arterial hypertension. J Am Coll Cardiol 2009;54:Suppl 1:S20-31.

24. Guilluy C, Eddahibi S, Agard C, et al. RhoA and Rho kinase activation in human pulmonary hypertension: role of 5-HT signaling. Am J Respir Crit Care Med 2009;179:1151-8.

25. Mair KM, MacLean MR, Morecroft I, Dempsie Y, Palmer TM. Novel interactions between the 5-HT transporter, 5-HT1B receptors and Rho kinase in vivo and in pulmonary fibroblasts. Br J Pharmacol 2008;155:606-16.

26. Tuder RM, Chacon M, Alger L, et al. Expression of angiogenesis-related molecules in plexiform lesions in severe pulmonary hypertension: evidence for a process of disordered angiogenesis. J Pathol 2001;195:367-74.

27. Dessouroux A, Akwa Y, Baulieu EE. DHEA decreases HIF-1alpha accumulation under hypoxia in human pulmonary artery cells: potential role in the treatment of pulmonary arterial hypertension. J Steroid Biochem Mol Biol 2008;109:81-9.

28. Bonnet S, Belus A, Hyvelin JM, Roux E, Marthan R, Savineau JP. Effect of chronic hypoxia on agonist-induced tone and calcium signaling in rat pulmonary artery. Am J Physiol Lung Cell Mol Physiol 2001;281:L193-201.

29. Bonnet S, Hyvelin JM, Bonnet P, Marthan R, Savineau JP. Chronic hypoxiainduced spontaneous and rhythmic contractions in the rat main pulmonary artery. Am J Physiol Lung Cell Mol Physiol 2001;281:L183-92.

30. Peng W, Hoidal JR, Karwande SV, Farrukh IS. Effect of chronic hypoxia on $\mathrm{K}+$ channels: regulation in human pulmonary vascular smooth muscle cells. Am J Physiol 1997;272(4 Pt 1):C1271-8.

31. Chevalier M, Gilbert G, Lory P, Marthan R, Quignard JF, Savineau JP. Dehydroepiandrosterone (DHEA) inhibits voltage-gated T-type calcium channels. Biochem Pharmacol 2012;83:1530-9. 
32. Williams MR, Dawood T, Ling S, et al. Dehydroepiandrosterone increases endothelial cell proliferation in vitro and improves endothelial function in vivo by mechanisms independent of androgen and estrogen receptors. J Clin Endocrinol Metab 2004;89:4708-15.

33. Bonnet S, Paulin R, Sutendra G, et al. Dehydroepiandrosterone reverses systemic vascular remodeling through the inhibition of the Akt/GSK3\{beta\}/NFAT axis. Circulation 2009;120:1231-40.

34. Dumas de La Roque E, Savineau JP, Metivier AC, et al. Dehydroepiandrosterone (DHEA) improves pulmonary hypertension in chronic obstructive pulmonary disease (COPD): a pilot study. Ann Endocrinol (Paris) 2012 73:20-5.

35. Bonnet S, Dubuis E, Vandier C, Martin S, Marthan R, Savineau JP. Reversal of chronic hypoxia-induced alterations in pulmonary artery smooth muscle electromechanical coupling upon air breathing. Cardiovasc Res 2002;53:1019-28.
36. Bonnet $\mathrm{P}$, Bonnet $\mathrm{S}$, Boissière $\mathrm{J}$, et al. Chronic hypoxia induces nonreversible right ventricle dysfunction and dysplasia in rats. Am J Physiol Heart Circ Physiol 2004;287:H1023-8.

37. Agard C, Rolli-Derkinderen M, Dumas-de-La-Roque E, et al. Protective role of the antidiabetic drug metformin against chronic experimental pulmonary hypertension. Br J Pharmacol 2009;158:1285-94.

38. Ducret T, El Arrouchi J, Courtois A, Quignard JF, Marthan R, Savineau JP. Stretch-activated channels in pulmonary arterial smooth muscle cells from normoxic and chronically hypoxic rats. Cell Calcium 2010;48:251-9.

39. Guibert C, Marthan R, Savineau JP. Angiotensin II-induced Ca(2+)-oscillations in vascular myocytes from the rat pulmonary artery. Am J Physiol 1996;270(4 Pt 1):L637-42.

40. Hamill OP, Marty A, Neher E, Sakmann B, Sigworth FJ. Improved patchclamp techniques for high-resolution current recording from cells and cellfree membrane patches. Pflugers Arch 1981;391:85-100. 